\title{
The Impact of COVID-19 on the Food Supply Chain and the Role of E-Commerce for Food Purchasing
}

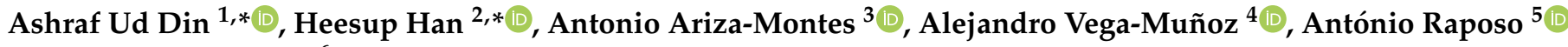 \\ and Shruti Mohapatra ${ }^{6}$
}

Citation: Din, A.U.; Han, H.; Ariza-Montes, A.; Vega-Muñoz, A.; Raposo, A.; Mohapatra, S. The Impact of COVID-19 on the Food Supply Chain and the Role of E-Commerce for Food Purchasing. Sustainability 2022, 14, 3074. https:// doi.org/10.3390/su14053074

Academic Editor: Arkadiusz Kawa

Received: 28 January 2022

Accepted: 2 March 2022

Published: 6 March 2022

Publisher's Note: MDPI stays neutral with regard to jurisdictional claims in published maps and institutional affiliations.

Copyright: (C) 2022 by the authors. Licensee MDPI, Basel, Switzerland. This article is an open access article distributed under the terms and conditions of the Creative Commons Attribution (CC BY) license (https:// creativecommons.org/licenses/by/ $4.0 /)$.
1 School of Transportation and Logistics, Southwest Jiaotong University, Chengdu 610031, China

2 College of Hospitality and Tourism Management, Sejong University, 98 Gunja-Dong, Gwanjin-Gu, Seoul 143-747, Korea

3 Social Matters Research Group, Universidad Loyola Andalucía, Escritor Castilla Aguayo 4, 14004 Córdoba, Spain; ariza@uloyola.es

4 Public Policy Observatory, Universidad Autónoma de Chile, 425 Pedro de Valdivia Avenue, Providencia, Santiago 7500912, Chile; alejandro.vega@uautonoma.cl

5 CBIOS (Research Center for Biosciences and Health Technologies), Universidade Lusófona de Humanidades e Tecnologias, Campo Grande 376, 1749-024 Lisboa, Portugal; antonio.raposo@ulusofona.pt

6 Faculty of Agriculture, Sri Sri University, Bidyadharpur Arilo, Cuttack 754006, Odisha, India; shrutimohapatra2015@gmail.com

* Correspondence: ashrafiawazir88@yahoo.com (A.U.D.); heesup.han@gmail.com (H.H.)

\begin{abstract}
The world has been plagued by an unforeseen threat to public health by the appearance of COVID-19, which has impacted the world's economy and the worldwide supply chain. The unexpected pandemic (COVID-19) quickly spread across the world, leaving not a single country unaffected by the worldwide pandemic. At the start of COVID-19, several countries adopted social distancing and lockdowns due to the virus. The existing pandemic's discriminatory aspect has a negative influence on human health and the standard of living, as well as worldwide trade, supply chains, and major economies. COVID-19 has been shown to have an effect throughout the broader food supply chain, one of the largest significant sectors of any country, from the field to the consumers. There are currently substantial concerns regarding food production, manufacturing, delivery, and consumption in light of emerging issues within the food supply chain. Limitations on the mobility of workers, variations in consumer demands, the shutdown of food manufacturing industries, limited food trading regulations, and financial stress throughout the food supply chain are all results of the COVID-19 pandemic. The pandemic (COVID-19) has changed consumer behavior and affected the business and economic sector. The purpose of this study was to explore the application of the Q-technique in the investigation of online consumer and manufacturer behavior in relation to end-user food purchases via digital marketing skills, supply chain possibilities, food purchaser and consumer happiness, and e-commerce infrastructure efficiency under the influence of COVID-19. The results show that in the crisis of supply chain management, clarifying the import food industry ecommerce supply chain crisis items, and determining their priority and strength can help enterprises make emergency decisions regarding supply chain operation; they can also be used as a reference for enterprises to use in responding to the crisis.
\end{abstract}

Keywords: COVID-19; supply chain; e-commerce; food purchasing

\section{Introduction}

Several countries worldwide recognized a state of health disaster as the COVID-19 virus spread extensively throughout six continents, and World Health Organization (WHO) advised that countries should prepare according to the Global Strategic Preparedness and Response Plan. To deal with COVID-19, governments have implemented social/physical separation and self-quarantine under public policy. This has caused an industrial slump [1-4]. 
The COVID-19 pandemic has affected where and how individuals shop for goods and has expedited major changes in industries that have affected everyone. The pandemic has impacted consumer pathways, how retailers interact with one another (business-tobusiness connections), and how businesses collaborate with direct suppliers, distributors, and wholesalers. Market manipulation, as a result of low sales volumes and hoarding, has also had an effect [5]. There is also a massive rise in internet buying activities as a result of the large number of people who are confined. Additionally, COVID-19 is known to have caused global economic instability and uncertainties. The virus disrupted the supply chain, altered customer behavior, and prompted concerns about rapid cross-functional style evaluation. In today's extremely dynamic market context, supply chain management (SCM) has emerged as a critical problem for long-term business growth. Enhancing corporate performance, in particular, is becoming a critical problem for long-term success [6].

Moreover, consumers do not give much thought to how the food on their tables is produced. Concerns about food safety in the midst of a global pandemic, on the other hand, have focused attention on the massive infrastructure and workforce responsible for ensuring a safe and reliable worldwide food supply. Consumer demand for food has increased, particularly at the start of this global crisis, and some store shelves have been temporarily emptied, resulting in excess purchases of essential products. However, despite this unprecedented demand, the food supply chain remained strong, since many supply chain contributors, including farmers, producers, distributors, and retailers, have worked hard to restock the shelves [7].

However, measures to effectively manage the COVID-19 pandemic in 2020 imprisoned several countries and seriously affected their economies. E-commerce has supported the restoration of several economies that have been hit with a significant public health crisis. E-commerce internet sales supply chains are severely impacted. COVID-19, in particular, has produced significant online sales demands for the international food industry and has created major problems for the supply chain. The global COVID-19 pandemic has transformed dynamic settings from an abstract idea to a tangible reality for everyone. Widespread restrictions on the movement of people, in particular, have had significant logistical consequences. The goal of this study was to look at the uses of the Q-technique for issue identification in the exported food industry's e-commerce logistics in a dynamic environment [8].

The data for end consumers before and after the COVID-19 outbreak shows notable changes. (1) Prior to the pandemic, user experience (reviews rating) had a strong favorable impact on the (relative) effectiveness of e-commerce platforms. Customer behavior has shifted as a result of the outbreak, and customers are now buying only what they want and need under specified circumstances [9-11]. Previous user experience (review ratings) has no impact in this scenario. Purchasing is dependent on what things are required at the time; (2) Prior to the pandemic, logistics outsourcing played a role in the association among reported supply chain competence and e-commerce platform (relative) effectiveness [12-14].

The association is the same before and post-COVID-19 epidemic, according to the findings. There is really no variation in the statistics during the pandemic for sellers either. Sellers are encouraged to produce products or run advertising campaigns for commodities that buyers require the most in this situation. In most industries, the economy is interrupted, and customers are concerned about the pandemic's impacts. As a result, their actions may shift (particularly at the problem recognition phase of a customer's decision-making process). Customers may purchase products required to support them in this situation, while rethinking and deferring purchases of desired items. The current pandemic's discriminatory nature has a negative impact on human health and living standards, as well as global trade, supply chains, and major economies. COVID-19 has been shown to have an effect throughout the broader food supply chain, from the field to consumers, on one of any country's most important sectors. In light of emerging issues in the food supply chain, there are currently significant concerns about food production, manufacturing, delivery, and 
consumption. Restrictions on the mobility of workers, changes in consumer demand, the closure of food manufacturing industries, limited food trading regulations, and financial stress throughout the food supply chain are all common outcomes of COVID-19.

The purpose of this study is to investigate how the COVID-19 epidemic has affected the behavior of online consumers and manufacturers through digital marketing capabilities, supply chain potential, food purchaser and consumer satisfaction, and e-commerce infrastructure efficiency as it relates to the end user's food purchasing effects. The paper is defined in six sections. In Section 1, a brief introduction of the present work is described. Section 2 presents the detailed literature background, investigating the pandemic's consequences on the food purchasing supply chain and online food market using hypotheses. Section 3 consists of a detailed analysis. Section 4 presents the results and a discussion, followed by the study analysis in Section 5 and a brief conclusion in Section 6.

\section{Literature Background}

With the emergence of COVID-19, the globe has been tormented by an unexpected risk to public health that has harmed the global economy and the supply chain. The unanticipated coronavirus (COVID-19) pandemic rapidly expanded over the globe, and not a single country remaining unaffected by this global pandemic. The larger areas of infection began implementing massive social limitations (known as PSSB) on 10 April 2020, and other areas quickly followed suit. With the first instance of COVID-19 in regions of the world, the need for manufactured foods and pharmaceutical items rose. These results are also in accordance with findings on COVID-19 multi-impact management and findings on COVID-19 pharmaceutical/healthcare process innovations.

\subsection{The Pandemic's Consequences on the Food Purchasing Supply Chain}

Agricultural production, post-harvesting management, manufacturing, distribution services, and usage of food products make up different phases within the supply chain. First, there are regulations that need to be followed by food companies and examined by the authorities. Considering the food supply chain, one of the most important sectors of the economy, it has been seen that COVID-19 has an impact on the entire process, from the field to the consumer. In light of recent challenges in food supply chain, there is now considerable concern about food production, processing, distribution, and demand. COVID-19 resulted in restrictions on the movement of workers, changes in the demands of consumers, the closure of food production facilities, restricted food trade policies, and financial pressures in the food supply chain [15-17]. Therefore, governments should facilitate the movement of workers and agri-food products. In addition, small farmers or vulnerable people should be supported financially. Facilities should change the working conditions and maintain the health and safety of employees by altering safety measures. Moreover, the pandemic also affects employees, as the virus spreads by human-to-human contact. Due to this reason, several governments closed their borders to the travel of workers; therefore, the supply chain has been highly affected. The COVID-19 virus has affected workers' health. Moreover, the virus spreads by close contact with others experiencing COVID-19 symptoms; therefore, worldwide governments imposed very serious limitations on the transportation of all types of products, including food items, via land, rail [18-23], sea, or air. According to recent studies, food item transportation via these vehicles decreased by $65 \%$ due to border restrictions.

The COVID-19 scenario has had a significant influence on a number of industries, including agriculture, planting, and harvesting. Furthermore, before the incidence of COVID-19, a manpower shortfall was already a serious problem [6,8]. As a result of the increased manpower shortfall generated by the virus and the physical separation which must be maintained during manufacturing, this issue has an impact on the ability of farming and food manufacturers to work effectively. Food and agricultural product distribution was restricted by such conditions, causing issues in assuring a consistent supply of food to consumers [24]. 
Considering the facts that numerous industries rely on vital supplies, most of these are highly sensitive to shortfalls, as their supply must come from domestic markets. Highvalue goods are additionally affected through logistical constraints that influence food supply platforms because of their short shelf life [25]. As a consequence, the food industry's logistic efficacy is crucial, especially during the above-mentioned global challenges. Two major important challenges within the food supply chain are obtaining raw materials from suppliers and ensuring food transfer from manufacturers to ultimate consumers. These problems are limiting the agricultural sectors' ability to operate normally, and they could have serious ripple effects regarding food quality, freshness, and health, limiting accessibility to markets and causing price increases [26,27]. Governments need to take serious initiatives to reconfigure food supply lines while they fight the virus. The volume and mixture of agriculture products that varies by item and country determines the impact of virus insecurities for farming production. For agricultural productivity, high-income countries often use capital-intensive approaches, whereas low-income countries depend mainly on manpower. As a result, the supply chain must be kept functioning, with a special emphasis on the fundamentals of logistical issues [15]. Although dynamic settings have been highlighted as an essential study component in earlier SCM crisis management investigations, it is rarely considered a crucial factor in actual crisis management approaches. The global COVID-19 pandemic, on the other hand, has transformed dynamic environments from an abstract idea to a tangible reality for everyone. Widespread restrictions on the movement of people, in particular, have had significant logistical consequences. Meat, fruit, vegetable, dairy, ready-to-eat foods, and other consumable items are all part of the food industry $[2,3]$.

Food and agriculture industries, on the other hand, can be classified under two types: capital investments and manpower. Wheat, corn, maize, soybeans, and oilseeds fall into the first sector. In the second, high-value items include fruits, vegetables, and fisheries. Limitations placed between towns, provinces, districts, and countries restrict the transportation of food products. As compared to essential items, acquiring large products demands a great amount of effort. As a result, the time-sensitive nature of agricultural operations, as well as the need for higher output growth, may contribute to agricultural sustainability through technical advancement and manpower upskilling.

The constraints posed by movement restrictions (national or international border closures) and fluctuations in consumer need are significant. Consumers were unable to eat outside due to these limitations and were required to cook their meals at home. Furthermore, because of the risk of contracting COVID-19 in stores, customers avoided going to markets and supermarkets. The supply chain has an impact on not only manufacturers, distributors, and users, but also on labor-intensive food processing companies. The productivity of many companies was decreased, stopped, or significantly delayed as a result of workers who were determined to be positive for COVID-19 or who were afraid of getting sick at work, primarily at meat-processing food industries at the time of the epidemic. Because of these factors, it is estimated that production capability fell about $25 \%$ in late April of 2020.

\subsection{The Online Food Market}

Consumer packaged product companies must reconsider their products in a new manner, particularly in terms of the online experience, information delivery, and how customers engage with physical food products. Because more people are adopting the use of mobile devices for shopping, food companies must consider the online shopping experience, whether it be on smartphones or computers, attentively. Online purchasing (and the related experience), which is boosted by the pandemic, is anticipated to continue to become a significant new source for food items and services post-pandemic. As per food, online grocery shopping increased by $55 \%$ in 2020, up from $44 \%$ in 2019. According to 2020 research on online purchasing, "factors influencing buyer willingness to switch to online purchases are including potential risk, price-search intention, mobility, and time 
of delivery," and "gender partially mediates the effects of behavior, design, and web appearance variables on shopping online concern. To make the transformation among online and offline shopping easier, online food retailers are focused on price, assortment, simplicity, and service" $[14,16,17]$. However, innovations in online shopping produces instability from known and routine behaviors, which can lead to increased risk levels, doubts, and distrust, which products and food marketers must be aware of.

Despite a plethora of studies on online customers and their preferences, the elements that impact buying behavior are still poorly understood. The studies that have been evaluated are extremely diverse, focusing on different aspects of online consumer behavior. As a result, a complete approach is required that takes into account the amount of technological instability, an individual's commitment to isolation, adaptation to online purchasing, the availability of an acceptable consumer experience, and decision-making speed. The presence of this knowledge gap necessitates a deep comprehensive exploration of online purchasing behavior under unstable pandemic conditions with respect to its key drivers.

The goal of this study is to create a composite measure of online purchasing behavior based on the drivers of the COVID-19 pandemic and then to use it to investigate the impact of COVID-19 on online consumer purchasing behavior, taking into account digital marketing competence, supply chain capability, customer satisfaction, and the effects of periodic discount rates and outsourced logistics. In the process of achieving this goal, the following six hypotheses (See Figure 1) were formed:

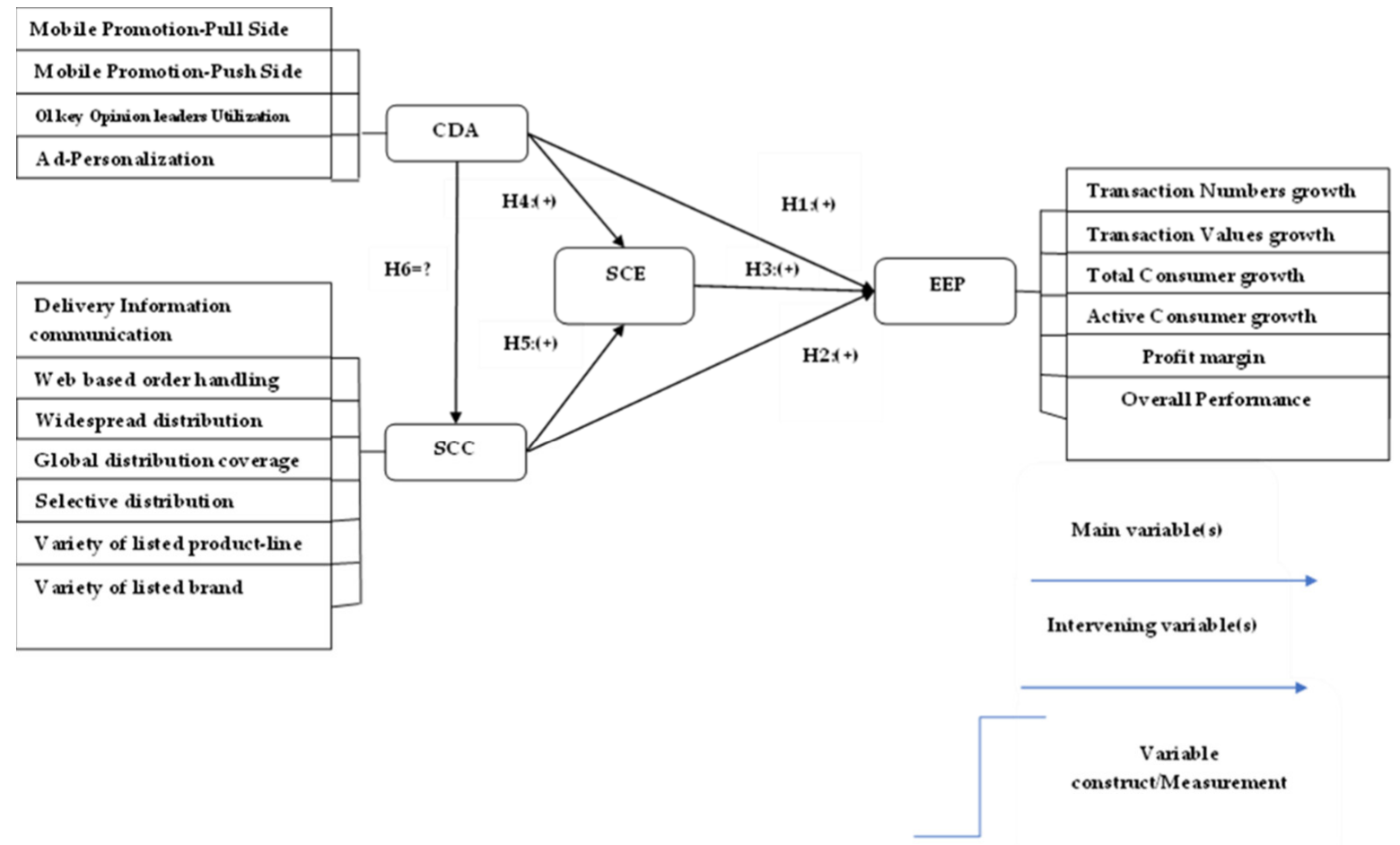

Figure 1. The hypotheses, study factors relationships, and significant results.

Hypothesis 1 (H1). Overall digital advertising potential is correlated to the performance of (relative) e-commerce platforms.

Hypothesis 1a (H1a). The association among perceived digital marketing and (relative) ecommerce business effectiveness is mediated by seasonal discount rates.

Hypothesis 2 (H2). E-commerce network competence has a significant connection with observed supply chain abilities. 
Hypothesis 2a (H2a). The correlation among social logistics capacity and (relative) e-commerce network effectiveness is mediated by logistics services.

Hypothesis 3 (H3). User satisfaction (reviews rating) is connected with (relative) e-commerce platform effectiveness.

Hypothesis 4 (H4). Buyer satisfaction (review ratings) is positively correlated with observed digital marketing potential.

Hypothesis $4 \mathbf{a} \mathbf{( H 4 a )}$. The correlation among observed digital marketing and buyer satisfaction (review ratings) is mediated by seasonal discount prices.

Hypothesis 5 (H5). Buyer satisfaction (review ratings) is positively correlated with observed supply chain capabilities.

Hypothesis 5a (H5a). The correlation between observed logistics capabilities and buyer experience (review ratings) is mediated by logistics services.

Hypothesis $\mathbf{6}$ (H6). There is no known relationship between observed digital marketing capabilities and observed supply chain capabilities.

\section{Methodology}

The Q-technique, also known as Q-method, or Q-sort, analyzes qualitative participant assessments in which participants describe their views using statements or observations [9]. The present study employed the Q-technique to rank claims made by e-commerce specialists for purchased foods in order to determine the value of connotative factors for food purchased by digital shopping, which has been impacted by COVID-19. The research consists of multiple data sets where the buying behavior of online customers using e-commerce websites before and throughout COVID-19 is examined. The first dataset is made up of e-commerce network end users. The second dataset is derived from end users who responded to the study's secondary phases recalling method (after the outbreak). The third set of data focuses on e-commerce network manufacturers. The fourth set of data included sellers who responded throughout the study's second stage (after the outbreak). The initial stage of the study is to create a questionnaire based on a research study conducted in prior studies. The questionnaire is distributed to respondents using data gathered from a diversity of groups. During data collection, the researcher conducted pilot testing and reliability validation on the questionnaires. The detailed steps of this methodology are shown in Table 1 and Flat sort in Figure 2.

\subsection{Steps in Methodology}

The steps in the methodology are: 1. Establish a Q-opinion parent group, 2. Obtain the Q-samples, and 3. Conduct a flat sort and Q-sort data analysis. Detained procedures are shown in Table 1.

\subsection{Questionnaire Design}

To gather prior data from participants and describe factor properties from the gathered data, we devised a questionnaire that corresponded to the Q-classifications [9]. The final survey included analytical research results, COVID-19 implications influencing the purchased food supply chain issue, and connotation statements gathered from interview sessions; the questionnaire is structured using a 9-point scale, as shown in Table 2. 
Table 1. The detailed methodology procedure.

Steps

1

2

3
Take Q samples

Flat sort

Q-sort data analysis
Description

This process is used, along with expert consultation, to obtain information used to construct a draft questionnaire for subsequent expert discussion.

The parent group statement is collected to accurately reflect the COVID-19 impact on crisis detection for the imported food industry's e-commerce supply chain.

The final declarative sentences chosen, after expert

consultation, followed the balance: positive $=18$, negative $=18$, and neutral $=11$. Professionals rated the placement of the Q-sample statements as

2-3-5-8-11-8-5-3-2, accordingly (see Figure 2; for example, 11 signifies a neutral place in the middle of 11 statements), and we increased the Q-classification dispersion table to fit nearly normally distributed criteria.

Respondent data was coded after expert classification, where score $=+4,+3, \ldots, 4$, corresponds to points $=9,8$, $\ldots, 1$, respectively. Our goal is to obtain the Q-sample categorization ranking chart for a professional Q-sort so that it can determine the impact of the COVID-19 crisis on the purchased food product supply chain.

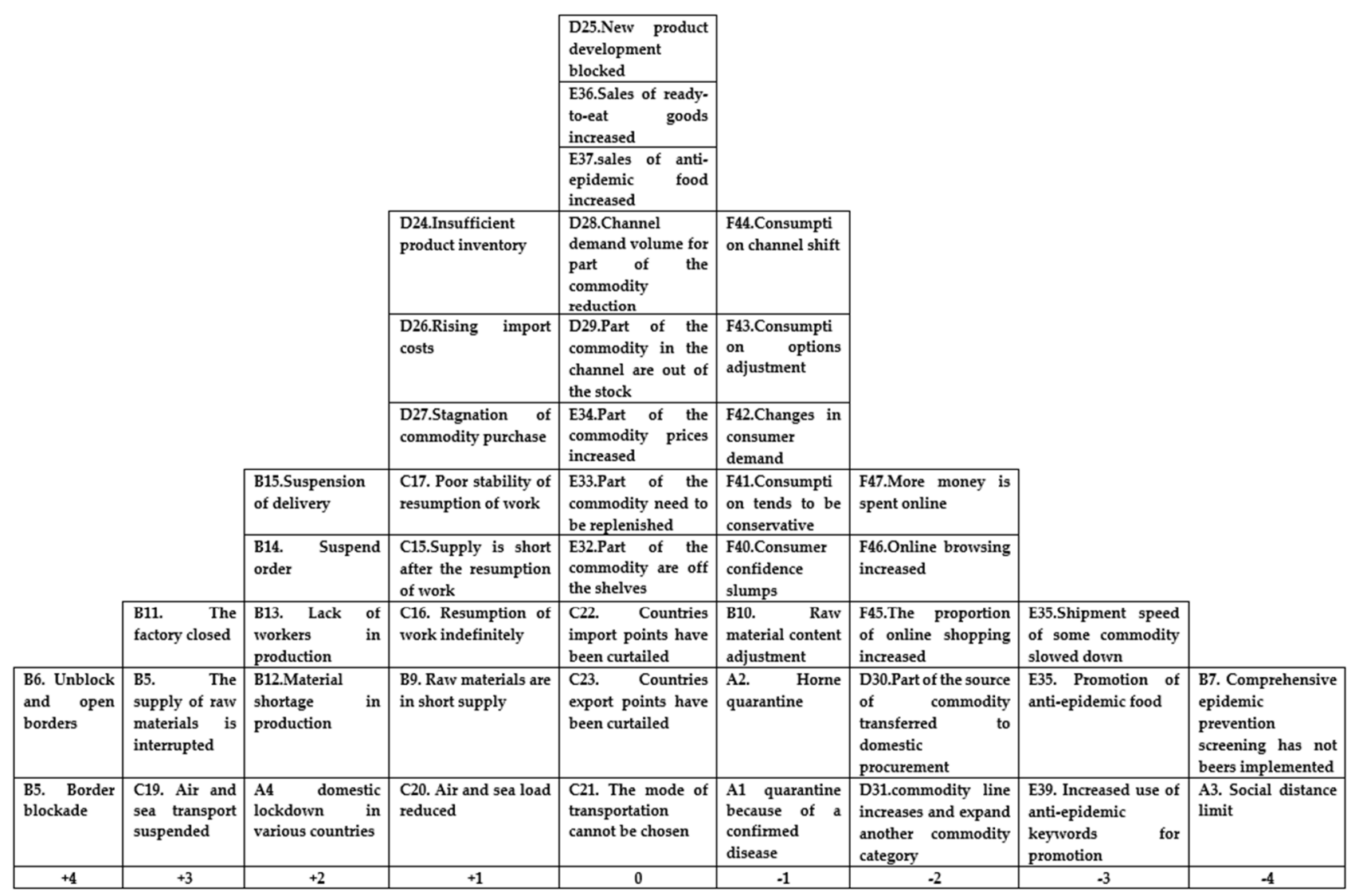

Figure 2. The analysis of the crisis in the supply chain using e-commerce. 
Table 2. The gender classification of the participants.

\begin{tabular}{cccccc}
\hline & & End Consumer Frequency & End Consumer \% & Seller Frequency & Seller \% \\
\hline \multirow{2}{*}{ Gender } & Male & 10 & 11 & 15 & 29 \\
& Female & 70 & 85 & 34 & 64 \\
\hline
\end{tabular}

\subsection{Data Gathering}

The questionnaire, which included Q-samples evaluated by specialists, is issued online to valid responders from randomized identified vendors, wholesalers, exporters, site owners, online shops, and logistics organizations involved in food imports. The goal of the data study is to identify items and their consequences for the influence of COVID-19 and its difficulties on import grocery retailers on the internet.

\section{Results and Discussion}

There are 1300 end consumers who completed the questionnaire during the first process of data collection (prior to the COVID-19 pandemic). Around 80 of these 1300 responders filled out the second stage of the questionnaire (after the COVID-19 pandemic), as mentioned in the Table 2 . There are 312 seller participants who completed the questionnaires during the first round. From the 312 participants who completed the second stage (after COVID-19 pandemic), during the third round, 56 completed the second survey.

To qualify for the survey, a participant must work for one of the top 20 digital commerce companies in the world. Amazon is the largest popular e-commerce site for both end users and vendors. End buyers used Amazon $86 \%$ of the time, while vendors used it $65 \%$ of the time. Items are removed from the end user and seller statistics when the component matrix outcome is less than 0.5. (Capacity for Digital Advertising) CDA 1, CDA 2, CDA 3, CDA 4, CDA 4, CDA 5, (Discount Pricing) DP 1, and DP 2 are the items shown in the end customer data. CRR 4 and CRR 5 are the items shown in the vendor data. Tables 3-6 show the validity of the leftover build items after the invalid data has been removed.

Table 3. Validity Scores for Capacity for Digital Advertising (CDA).

\begin{tabular}{ccc}
\hline & Prior to COVID & Seller before \\
\cline { 2 - 3 } & Component Matrix & Component Matrix \\
\hline CDA 1 & & 0.814 \\
CDA 2 & 0.742 & 0.741 \\
CDA 3 & 0.785 & 0.845 \\
CDA 4 & 0.842 & 0.774 \\
CDA 5 & 0.751 & 0.810 \\
\hline
\end{tabular}

Table 4. Validity Scores for Supply Chain Capacity (SCC).

\begin{tabular}{ccc}
\hline & Prior to COVID & Seller before \\
\cline { 2 - 3 } & Component Matrix & Component Matrix \\
\hline SCC 1 & 0.574 & 0.579 \\
SCC 2 & 0.704 & 0.628 \\
SCC 3 & 0.665 & 0.745 \\
SCC 4 & 0.478 & 0.664 \\
SCC 5 & 0.527 & 0.540 \\
\hline
\end{tabular}


Table 5. Validity Scores for Consumer Experience (SCE).

\begin{tabular}{ccc}
\hline & Prior to COVID & Seller before \\
\cline { 2 - 3 } & Component Matrix & Component Matrix \\
\hline SCE 1 & 0.492 & 0.752 \\
SCE 2 & 0.823 & 0.807 \\
SCE 3 & 0.575 & 0.564 \\
SCE 4 & 0.589 & 0.758 \\
SCE 5 & 0.712 & 0.632 \\
\hline
\end{tabular}

Table 6. Validity Scores for Effectiveness of E-commerce Platforms (EEP).

\begin{tabular}{ccccc}
\hline & Pridor to COVID & After COVID & Seller before & After COVID \\
\cline { 2 - 5 } & $\begin{array}{c}\text { Component } \\
\text { Matrix }\end{array}$ & $\begin{array}{c}\text { Component } \\
\text { Matrix }\end{array}$ & $\begin{array}{c}\text { Component } \\
\text { Matrix }\end{array}$ & $\begin{array}{c}\text { Component } \\
\text { Matrix }\end{array}$ \\
\hline EEP 1 & 0.780 & 0.889 & 0.621 & 0.850 \\
EEP 2 & 0.601 & 0.744 & 0.545 & 0.740 \\
EEP 3 & 0.689 & 0.854 & 0.756 & 0.825 \\
EEP 4 & 0.790 & 0.851 & 0.542 & 0.721 \\
EEP 5 & 0.809 & 0.954 & 0.700 & 0.832 \\
\hline
\end{tabular}

Figure 3 shows the regression outcome after applying SPSS on the current developed research. Many hypotheses are eliminated because they have zero significant impact, according to the regression results. There are also some conflicts between data collected before and during the COVID-19 pandemic.
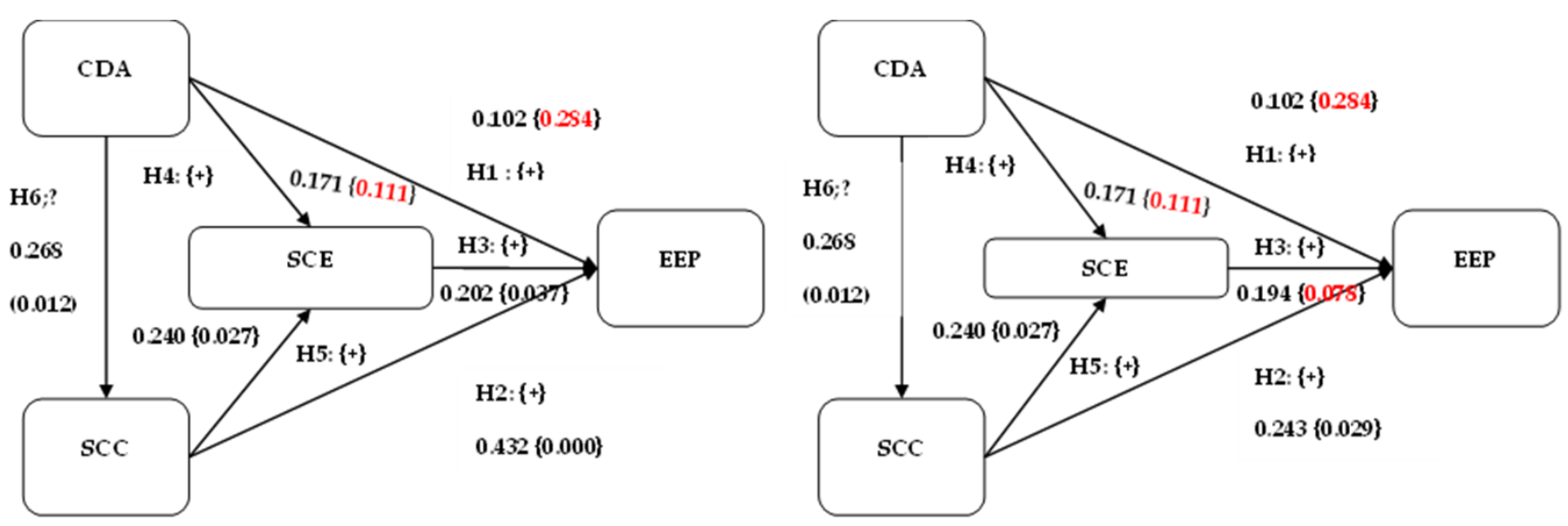

[a]

[b]

Figure 3. The beta and sign throughput end-user information: (a) prior COVID-19; (b) post COVID-19.

\subsection{E-Commerce System Efficiency and Capacity for Digital Advertising (H1 and H1a)}

$\mathrm{H} 1$ has been discarded, according to data collected from end users and vendors before and after the COVID-19 pandemic. This suggests that the observed digital advertising capabilities have had minimal impact on the effectiveness of (relative) (e-commerce platforms. This is applicable for both end buyers and retailers before and after the COVID-19 pandemic. Internet marketing practices, including digital marketing, may have seemed unnecessary in the process of problem identification due to internal factors (such as depleted inventories, frustration, new requirements, and assorted foods) or external factors (including digital marketing). It is believed that the participant samples for this research 
purchase items on an e-commerce site in response to an internal factor rather than external factors. As a result, perceived digital marketing has little bearing on the (relative) success of e-commerce platforms. Because sales advertising is primarily an external factor in the crisis identification stage, it does not mitigate the association between the two. The data before and after the COVID-19 pandemic indicated no significant differences.

\subsection{E-Commerce Network Effectiveness and Expected Supply Chain Capabilities (H2 and H2a)}

In the context of end user data before and after the COVID-19 pandemic, the results revealed that $\mathrm{H} 2$ is recognized as the sign and $\leq 0.05$ as an outcome. As a result, observed supply chain capacity has a considerable beneficial impact on the (relative performance of) e-commerce platforms. $\mathrm{H} 2$ is ignored as an indication, according to data collected from sellers before and after the COVID-19 pandemic, with $\geq 0.05$ as an outcome; furthermore, before the COVID-19 pandemic, logistics management had an intervening influence among observed supply chain capabilities and e-commerce network effectiveness(relatively), although only for end consumers. End-user data collected following the COVID-19 pandemic, on the other hand, shows that observed supply chain functionality has no impact on ecommerce network (relative) effectiveness. Before and after the COVID-19 pandemic, the outcome for sellers was the same.

\subsection{E-Commerce Network Effectiveness and Customer Feedback Rating (H3)}

In the statistics for end users and sellers prior to the pandemic, shown in Figure 3a,b, $\mathrm{H} 3$ is regarded as the sign, with the outputs shown as $\leq 0.05$. As a result, it can be argued that user feedback ratings have a significant impact on the (relative) performance of ecommerce platforms. After the pandemic, however, the data from end users and sellers suggest that $\mathrm{H} 3$ is ignored as an indicator, with an outcome of $\geq 0.05$. As a result, it may be stated that user experience has no major impact on the (relative) effectiveness of e-commerce platforms. Regarding the consumer decision-making process, the first stage, issue identification, might be triggered by an internal stimulation, such as a new need or want. Following the COVID-19 pandemic, some users' behaviors, as well as their demands and desires, changed. Buyers are more anxious regarding their health and the outbreak's financial effects (Accenture, 2020a). User feedback ratings may have an impact on e-commerce platform (relative) effectiveness prior to the epidemic, but not afterwards. It is possible that their needs and wants are fluctuating, therefore they purchase the items that they require the most. Many sellers respond to this, which might explain why buyer review scores are not affected.

\subsection{Client Evaluation Rating and Reported Digital Marketing Capabilities ( $\mathrm{H} 4$ and $\mathrm{H} 4 \mathrm{a}$ )}

H4 and H4a are not substantial in the data from end consumers before and after the pandemic. That is, consumer experiences (reviews scores) are unchanged by observed online marketing capabilities, and there are no intermediary effects of regular vs. discount price. $\mathrm{H} 4$ is recognized by the sellers, according to data collected prior and during the pandemic, while $\mathrm{H} 4 \mathrm{a}$ is not. This suggests that observed online marketing capabilities have a considerable positive impact on customer experiences (reviews scores), but that regular vs. discount price has no effect on the two. Although there is a variation in the outcomes before and after the pandemic, there is a huge difference in the outcomes for end buyers and retailers. The observed internet marketing capabilities have a meaningful impact on the consumer experience (review ratings). The sellers, on the other hand, are severely impacted. This, according to the vendors, might be due to an effective internet marketing campaign providing a stimulation to their buyers' experience. 


\subsection{Customer Evaluation Ratings and Expected Supply Chain Capabilities (H5 and H5a)}

$\mathrm{H} 5$ is recognized as the sign, according to the regression results of end consumer and vendor data before and after the COVID-19 pandemic. H5a is not significant, although the output is $\leq 0.05$. It can be determined that observed supply chain capabilities have a strong beneficial impact on buyer experiences (reviews scores). Before and after the pandemic, there are no differences in the outcomes for end users and vendors. Buyers are always worried about when their item will be delivered, so anticipated supply chain capabilities can affect the user experience (reviews scores). Furthermore, distribution procedures have been affected as a result of the pandemic and government regulations, such as geographical limitations.

\subsection{Observed Supply Chain Capability and Estimated Digital Marketing Capabilities (H6)}

Figure 3 illustrates how $\mathrm{H} 6$ is recognized as the sign, based on the regression results, with $\leq 0.05$ as an outcome. This suggests that observed digital marketing capability is linked to observed supply chain capabilities in a positive way. A supply chain marketing strategy is a powerful instrument for acquiring customers, both before and after the pandemic. Geographical distances, time constraints, and limited mobility are all factors. Because of the supply chain disruptions caused by the pandemic, the regulations for when personnel in working in areas such as inventory, products, and retail locations should work online are shifting. Throughout the pandemic, businesses took advantage of possibilities to optimize price offers and discounts for important buyers and locations in order to boost sales throughout the economic downturn.

Quality goods and a connection to resources accounted for $65.6 \%$ of the significant priority rating for the identification of problems in the e-commerce supply chain for goods imported in the food sector. As a result, resource owners' tendencies have an impact on industry development, with stakeholders emerging as the biggest beneficiaries of supply chain issues. Expert interviews revealed that organizations and operators remained significantly reliant on manufacturing and logistics to obtain commodities for every producer within the supply chain. To overcome supply chain disruption produced by the COVID-19 epidemic, many cross-border e-commerce businesses seek other businesses with production capabilities or commodity sources as replacements, building short-chains to shift orders. The impacts of a sudden crisis are investigated in this research, with a focus on identification after the problem has occurred. The Q-technique method is a study designed to take into account subjective perspectives, while also allowing for qualitative interviews and statistical surveys. It is more difficult for people and goods to move throughout the world as a result of COVID-19, and supply chain crisis response is confronting unprecedented hurdles. To extract extensive and in-depth information, this research combined comments from first-line operators and related employees, and used the Q-technique to identify supply chain problems, gathering strategies and perspectives for improvement in imported food e-commerce enterprises. Table 7 reveals the extracted factors using eigenvalue. 
Table 7. The components matrix as per the factors.

\begin{tabular}{|c|c|c|c|c|c|c|c|c|c|c|}
\hline \multirow{2}{*}{$\begin{array}{c}\text { Items } \\
\text { C19 }\end{array}$} & \multicolumn{10}{|c|}{ Factors } \\
\hline & 0.655 & 0.152 & 0.260 & 0.015 & -0.104 & 0.025 & 0.104 & -0.025 & 0.101 & 0.207 \\
\hline c21 & 0.25 & 0.054 & 0.107 & -0.104 & -0.028 & 0.254 & 0.271 & -0.058 & 0.171 & -0.105 \\
\hline c16 & 0.541 & 0.350 & 0.107 & 0.125 & -0.150 & 0.354 & -0.125 & 0.204 & 0.057 & 0.109 \\
\hline $\mathrm{c} 20$ & 0.525 & 0.056 & 0.191 & 0.182 & -0.085 & 0.157 & 0.144 & -0.018 & 0.148 & 0.153 \\
\hline c22 & 0.582 & 0.167 & 0.125 & 0.148 & 0.126 & -0.157 & 0.416 & 0.159 & 0.150 & 0.140 \\
\hline c17 & 0.542 & 0.145 & 0.194 & 0.295 & 0.174 & -0.155 & 0.192 & 0.118 & -0.159 & -0.270 \\
\hline b15 & 0.425 & 0.254 & 0.170 & 0.149 & -0.059 & 0.142 & -0.274 & 0.290 & 0.102 & -0.047 \\
\hline $\mathrm{d} 24$ & 0.414 & 0.247 & 0.159 & 0.121 & 0.178 & 0.108 & 0.213 & 0.141 & 0.371 & 0.159 \\
\hline b14 & 0.495 & 0.192 & 0.157 & 0.257 & 0.148 & 0.252 & -0.211 & 0.425 & -0.048 & -0.047 \\
\hline$c 23$ & 0.461 & 0.226 & 0.341 & -0.171 & 0.144 & 0.109 & 0.121 & 0.141 & 0.201 & -0.141 \\
\hline c18 & 0.230 & 0.121 & 0.210 & 0.252 & 0.157 & -0.135 & 0.182 & 0.124 & -0.107 & -0.107 \\
\hline b9 & 0.152 & 0.716 & 0.150 & 0.255 & 0.150 & 0.295 & 0.105 & 0.107 & 0.214 & 0.120 \\
\hline b10 & 0.252 & 0.541 & 0.270 & -0.110 & 0.104 & 0.194 & 0.115 & -0.117 & -0.125 & -0.115 \\
\hline $\mathrm{b} 8$ & 0.251 & 0.532 & 0.146 & 0.174 & 0.104 & 0.170 & -0.275 & 0.107 & 0.125 & 0.141 \\
\hline b11 & 0.215 & 0.454 & -0.154 & 0.135 & -0.157 & 0.134 & -0.145 & 0.170 & 0.158 & 0.125 \\
\hline e34 & 0.112 & 0.275 & 0.152 & 0.174 & 0.019 & 0.145 & 0.270 & 0.254 & 0.147 & -0.115 \\
\hline $\mathrm{f} 46$ & 0.185 & 0.107 & 0.472 & 0.207 & -0.120 & 0.157 & -0.146 & 0.109 & -0.101 & 0.124 \\
\hline $\mathrm{f} 47$ & 0.271 & 0.205 & 0.615 & -0.152 & 0.145 & 0.274 & 0.156 & 0.157 & -0.125 & 0.104 \\
\hline $\mathrm{f} 45$ & 0.254 & 0.147 & 0.710 & 0.174 & 0.145 & 0.225 & -0.073 & 0.107 & 0.101 & -0.110 \\
\hline $\mathrm{f} 44$ & 0.142 & 0.157 & 0.421 & 0.151 & 0.342 & 0.451 & 0.247 & 0.256 & 0.171 & -0.215 \\
\hline $\mathrm{f} 43$ & 0.142 & 0.405 & 0.421 & 0.452 & 0.212 & 0.152 & 0.054 & 0.074 & 0.144 & -0.105 \\
\hline $\mathrm{f} 42$ & 0.115 & 0.154 & 0.275 & 0.115 & 0.114 & 0.222 & 0.256 & 0.144 & 0.244 & -0.142 \\
\hline $\mathrm{f} 41$ & 0.142 & 0.242 & 0.345 & 0.560 & 0.242 & 0.175 & 0.247 & 0.164 & 0.252 & 0.147 \\
\hline $\mathrm{f} 40$ & 0.071 & 0.093 & 0.297 & 0.745 & 0.179 & 0.141 & 0.286 & 0.130 & 0.187 & 0.170 \\
\hline b13 & 0.215 & 0.154 & -0.105 & 0.254 & 0.273 & 0.342 & -0.178 & 0.126 & -0.213 & -0.147 \\
\hline b12 & 0.342 & 0.243 & -0.125 & 0.456 & 0.195 & 0.141 & 0.155 & 0.175 & -0.146 & 0.107 \\
\hline a1 & -0.129 & -0.155 & -0.126 & 0.255 & 0.414 & 0.235 & 0.246 & 0.125 & 0.485 & -0.142 \\
\hline a2 & 0.115 & -0.124 & 0.162 & 0.145 & 0.517 & 0.256 & 0.105 & 0.124 & 0.155 & 0.114 \\
\hline a3 & 0.246 & 0.155 & 0.256 & 0.150 & 0.525 & 0.126 & 0.135 & 0.156 & 0.125 & -0.155 \\
\hline b5 & 0.252 & 0.256 & 0.252 & 0.105 & 0.558 & 0.162 & -0.167 & 0.106 & 0.158 & 0.149 \\
\hline b7 & 0.255 & 0.235 & -0.244 & -0.125 & 0.525 & 0.156 & 0.154 & -0.156 & -0.121 & -0.156 \\
\hline b6 & -0.161 & 0.177 & 0.264 & -0.163 & 0.541 & 0.255 & -0.125 & -0.245 & -0.140 & 0.141 \\
\hline $\mathrm{a} 4$ & 0.105 & 0.241 & 0.255 & 0.160 & 0.526 & 0.260 & 0.277 & 0.125 & -0.361 & -0.123 \\
\hline e38 & 0.252 & 0.256 & 0.252 & 0.105 & 0.558 & 0.162 & -0.167 & 0.106 & 0.158 & 0.149 \\
\hline e37 & -0.129 & -0.155 & -0.126 & 0.255 & 0.414 & 0.235 & 0.246 & 0.125 & 0.485 & -0.142 \\
\hline e39 & 0.142 & 0.242 & 0.345 & 0.560 & 0.242 & 0.175 & 0.247 & 0.164 & 0.252 & 0.147 \\
\hline e36 & 0.185 & 0.107 & 0.472 & 0.207 & -0.120 & 0.157 & -0.146 & 0.109 & -0.101 & 0.124 \\
\hline $\mathrm{d} 30$ & 0.125 & -0.124 & -0.135 & 0.154 & 0.102 & 0.245 & 0.426 & 0.125 & -0.126 & 0.155 \\
\hline $\mathrm{d} 31$ & 0.252 & 0.256 & 0.252 & 0.105 & 0.558 & 0.162 & -0.167 & 0.106 & 0.158 & 0.149 \\
\hline $\mathrm{d} 25$ & 0.215 & 0.532 & 0.146 & 0.174 & 0.104 & 0.170 & -0.275 & 0.107 & 0.125 & 0.141 \\
\hline e32 & 0.105 & 0.241 & 0.255 & 0.160 & 0.526 & 0.260 & 0.277 & 0.125 & -0.361 & -0.123 \\
\hline e33 & 0.185 & 0.107 & 0.472 & 0.207 & -0.120 & 0.157 & -0.146 & 0.109 & -0.101 & 0.124 \\
\hline e35 & -0.161 & 0.177 & 0.264 & -0.163 & 0.541 & 0.255 & -0.125 & -0.245 & -0.140 & -0.141 \\
\hline $\mathrm{d} 27$ & 0.325 & 0.055 & 0.224 & 0.189 & 0.173 & 0.195 & 0.143 & 0.293 & 0.562 & 0.148 \\
\hline $\mathrm{d} 26$ & 0.185 & 0.107 & 0.472 & 0.207 & -0.120 & 0.157 & -0.146 & 0.109 & -0.101 & 0.124 \\
\hline $\mathrm{d} 29$ & 0.404 & 0.293 & 0.055 & 0.224 & 0.189 & 0.173 & 0.195 & 0.143 & 0.177 & 0.410 \\
\hline $\mathrm{d} 28$ & 0.325 & 0.055 & 0.224 & 0.189 & 0.173 & 0.195 & 0.143 & 0.293 & 0.562 & 0.415 \\
\hline
\end{tabular}

\section{Study Analysis}

The consequences of the COVID-19 virus for food retail stores (SCs) and their resilience are explored in this research by using real-life pandemic situations as the inspiration. With the use of any logistics supply chain digital twin, we designed and used a discrete-event modeling study for SC operations and efficiency patterns. The findings of our research could help food retail SCs become more resilient in the face of future pandemics and pandemic-like situations. This study is formulated to overcome these gaps in the research. 


\section{Conclusions}

The imported food industry e-commerce supply chain is facing a pronounced impact on business challenges due to adverse environmental conditions, such as border blockades caused by COVID-19. This study used the Q-technique to investigate crisis detection for the imported food industry supply chain.

The study results established a set of 47 statements describing aspects of e-commerce supply chain impacted by COVID-19 that imported food e-commerce enterprises should recognize. Each statement was ranked by the perceived severity of the crisis to facilitate practical application for e-commerce business operators, and the factor strengths provide a reference for examining the supply chain crisis.

The cross-border e-commerce supply chain crisis detection results can be used as a practical operational basis for imported food e-commerce enterprise managers to examine their supply chain crisis tolerance and response. One drawback of this study is the small number of people who took part in the survey. The data was obtained near the onset of the COVID-19 outbreak, which is a second constraint. In future studies, it is advised that the sample size be increased, that the three phases of COVID-19 be studied, and that the data be processed using structural equation modeling (SEM) to examine how the findings change.

Author Contributions: Conceptualization, A.U.D. and S.M.; data curation A.A.-M.; formal analysis, A.A.-M.; resources, A.V.-M.; supervision, H.H. and S.M.; writing-review and editing, A.U.D.; software, A.R. and S.M. All authors have read and agreed to the published version of the manuscript.

Funding: This research received no external funding.

Institutional Review Board Statement: Not applicable.

Informed Consent Statement: Not applicable.

Data Availability Statement: The data of this study can be provided upon reasonable request to the corresponding author.

Conflicts of Interest: The authors declare that there is no conflict of interest.

\section{References}

1. Agarwal, K.M.; Mohapatra, S.; Sharma, P.; Sharma, S.; Bhatia, D.; Mishra, A. Study and overview of the novel corona virus disease (COVID-19). Sensors Int. 2020, 1, 100037. [CrossRef] [PubMed]

2. Agrahari, R.; Mohanty, S.; Vishwakarma, K.; Nayak, S.K.; Samantaray, D.; Mohapatra, S. Update vision on COVID-19: Structure, immune pathogenesis, treatment and safety assessment. Sensors Int. 2021, 2, 100073. [CrossRef] [PubMed]

3. Andersen, K.G.; Rambaut, A.; Lipkin, W.I.; Holmes, E.C.; Garry, R.F. The proximal origin of SARS-CoV-2. Nat. Med. 2020, 26, 450-452. [CrossRef] [PubMed]

4. Behloul, N.; Baha, S.; Shi, R.; Meng, J. Role of the GTNGTKR motif in the N-terminal receptor-binding domain of the SARS-CoV-2 spike protein. Virus Res. 2020, 286, 198058. [CrossRef]

5. Helm, D. The Environmental Impacts of the Coronavirus. Environ. Resour. Econ. 2020, 76, 21-38. [CrossRef]

6. Hu, B.; Guo, H.; Zhou, P.; Shi, Z.-L. Characteristics of SARS-CoV-2 and COVID-19. Nat. Rev. Microbiol. 2021, 19, 141-154. [CrossRef]

7. Johnson, M.C.; Lyddon, T.D.; Suarez, R.; Salcedo, B.; LePique, M.; Graham, M.; Ricana, C.; Robinson, C.; Ritter, D.G. Optimized Pseudotyping Conditions for the SARS-COV-2 Spike Glycoprotein. J. Virol. 2020, 94, e01062-20. [CrossRef]

8. Lvov, D.K.; Alkhovsky, S.V. Source of the COVID-19 pandemic: Ecology and genetics of coronaviruses (Betacoronavirus: Coronaviridae) SARS-CoV, SARS-CoV-2 (subgenus Sarbecovirus), and MERS-CoV (subgenus Merbecovirus). Vopr. Virusol. 2020, 65, 62-70. [CrossRef]

9. Ma, Q.; Chang, C.-C.; Lin, C.-T. Detecting the Crisis of Supply Chain Management on E-Commerce for Sustainability Using Q-Technique. Sustainability 2021, 13, 9098. [CrossRef]

10. Mohapatra, S.; Priyanka, V.; Mohapatra, S.; Kohli, I.; Mishra, R.K. Impact of corona virus covid-19 on the global economy. Int. J. Agric. Stat. Sci. 2020, 16, 771-778.

11. Mohapatra, S.; Mishra, Y.; Dash, L. COVID-19: Analysing the Legal Nuances of the Lockdown Order. Indian J. Forensic Med. Toxicol. 2020, 14, 612-616. [CrossRef]

12. Rosenbloom, D.; Markard, J. A COVID-19 recovery for climate. Science 2020, 368, 447. [CrossRef] [PubMed]

13. Rugani, B.; Caro, D. Impact of COVID-19 outbreak measures of lockdown on the Italian Carbon Footprint. Sci. Total Environ. 2020, 737, 139806. [CrossRef] [PubMed]

14. Singhal, T. A Review of Coronavirus Disease-2019 (COVID-19). Indian J. Pediatr. 2020, 87, 281-286. [CrossRef] 
15. FAO. COVID-19 and Smallholder Producers' Access to Markets; FAO: Rome, Italy, 2020; ISBN 978-92-5-132414-1.

16. Tan, H.W.; Xu, Y.; Lau, A.T.Y. Angiotensin-converting enzyme 2: The old door for new severe acute respiratory syndrome coronavirus 2 infection. Rev. Med. Virol. 2020, 30, e2122. [CrossRef]

17. University, J.H. COVID-19 Dashboard by the Center for Systems Science and Engineering (CSSE). Available online: https: / / coronavirus.jhu.edu/map.html (accessed on 26 January 2020).

18. Sharma, S.K.; Mohapatra, S.; Sharma, R.C.; Alturjman, S.; Altrjman, C.; Mostarda, L.; Stephan, T. Retrofitting Existing Buildings to Improve Energy Performance. Sustainability 2022, 14, 666. [CrossRef]

19. Sharma, S.K.; Sharma, R.C.; Lee, J. Effect of Rail Vehicle-Track Coupled Dynamics on Fatigue Failure of Coil Spring in a Suspension System. Appl. Sci. 2021, 11, 2650. [CrossRef]

20. Sharma, S.K.; Sharma, R.C.; Lee, J. In situ and experimental analysis of longitudinal load on carbody fatigue life using nonlinear damage accumulation. Int. J. Damage Mech. 2021, 105678952110460. [CrossRef]

21. Bhardawaj, S.; Sharma, R.; Sharma, S. Ride Analysis of Track-Vehicle-Human Body Interaction Subjected to Random Excitation. J. Chin. Soc. Mech. Eng. 2020, 41, 229-238. [CrossRef]

22. Bhardawaj, S.; Sharma, R.C.; Sharma, S.K. Development of multibody dynamical using MR damper based semi-active bio-inspired chaotic fruit fly and fuzzy logic hybrid suspension control for rail vehicle system. Proc. Inst. Mech. Eng. Part K J. Multi-Body Dyn. 2020, 234, 723-744. [CrossRef]

23. Sharma, S.K.; Lee, J. Design and Development of Smart Semi Active Suspension for Nonlinear Rail Vehicle Vibration Reduction. Int. J. Struct. Stab. Dyn. 2020, 20, 2050120. [CrossRef]

24. Lin, Y.; Marjerison, R.K.; Choi, J.; Chae, C. Supply Chain Sustainability during COVID-19: Last Mile Food Delivery in China. Sustainability 2022, 14, 1484. [CrossRef]

25. Wang, S. Assessing the Food Safety and Quality Assurance System during the COVID-19 Pandemic. Sustainability 2022, $14,1507$. [CrossRef]

26. Tort, Ö.Ö.; Vayvay, Ö.; Çobanoğlu, E. A Systematic Review of Sustainable Fresh Fruit and Vegetable Supply Chains. Sustainability 2022, 14, 1573. [CrossRef]

27. Hyland, J.J.; Macken-Walsh, Á. Multi-Actor Social Networks: A Social Practice Approach to Understanding Food Hubs. Sustainability 2022, 14, 1894. [CrossRef] 